\title{
Highlighting reviews
}

\author{
David Archer · Danny Rangasamy
}

Published online: 25 November 2010

(C) Springer Science+Business Media B.V. 2010

Biotechnology Letters has an established position amongst the top rapid-publication biotechnology journals offering rapid assessment of submitted papers and a wide audience for the published papers. The impact factor of the journal has steadily increased in recent years to 1.636 as have the numbers of downloads of articles that are consistently over 25000 per month suggesting a very high impact of published articles in both research groups and in industrial laboratories.

The introduction of mini-reviews in 2003 has proven to be a well-received development in the Journal and has resulted in a step-improvement in the journal's impact factor. Although most of the published reviews are invited ones, we extend this invitation to all our readers to submit a review manuscript for consideration of publication in the Journal. Some of the major reviews that we have published in recent years have provided key information on such widely-diverse topics as:

- Gene therapy of glioma cancer (Fu et al. 2010),

- Sortase-mediated protein ligation (Proft 2010),

- Purification of natural products ( $\mathrm{Li}$ and Chase 2010),

D. Archer $(\square)$

School of Biology, University of Nottingham,

Nottingham NG7 2RD, UK

e-mail: david.archer@nottingham.ac.uk

D. Rangasamy

John Curtin School of Medical Research, Australian

National University, Canberra, ACT, Australia
- Therapeutic antibodies (Constantinou et al. 2010),

- Metagenomics (Chistoserdova 2010),

- Biopolymer gels in regenerative medicine (Hunt and Grover 2010),

- Biotransformation of organofluorine compounds (Murphy 2010),

- $\quad \mathrm{N}$-Linked glycoengineering for human therapeutic proteins (Pandhal and Wright 2010),

- Delivery of therapeutic proteins (Stolnik and Shakesheff 2009),

- Genetic engineering of millet (Ceasar and Ignacimuthu 2009),

- Plant phopholipases (Mansfeld 2009),

- Bone regeneration and repair (Haidar et al. 2009a, b)

- Microalgal biotechnology (Eriksen 2008),

- Metabolic flux analysis (Iwatani et al. 2008),

- Microbial metabolomics (Mashego et al. 2007),

- Hyaluronic acid for biomedical and industrial applications (Kogan et al. 2007).

In keeping with our desire to inform the biotechnology fraternity of current developments and activities in biotechnology, we invite those readers of this Journal, who consider that their own expertise in a particular field should be shared with other likeminded researchers, to submit a mini-review to us for consideration.

Manuscripts should be submitted on-line in the usual manner and in the style that is described in the Instructions to Authors (downloadable from our website), but authors may choose to seek an initial 
opinion on the scope of their intended review by contacting either of the two reviews editors (david. archer@nottingham.ac.uk or danny.rangasamy@anu. edu.au). Review articles are short (normally no more than 3500 words) and should provide insight, based on a critical assessment of the literature, on topics relevant to biotechnology. We remind our readers that we now have specific sections within the Journal to cover the major aspects of biotechnology:

- Animal Cell Technology;

- Bioprocessing and Biological Engineering;

- Biofuels and Environmental Biotechnology;

- Microbial and Enzyme Technology;

- Plant Cell Technology; and

- Regenerative Medicine and Biomaterials.

However, we are well-aware that many key developments lie at the interface of two or more of these sections and therefore these sections are not absolute criteria for consideration of a review for inclusion in the Journal. Inter-disciplinary reviews are therefore especially welcome.

On behalf of the executive editors of Biotechnology Letters, we look forward to receiving your manuscript.

\section{References}

Ceasar SA, Ignacimuthu S (2009) Genetic engineering of millets: current status and future prospects. Biotechnol Lett 31:779-788

Chistoserdova L (2010) Recent progress and new challenges in metagenomics for biotechnology. Biotechnol Lett 32: $1351-1359$
Constantinou A, Chen C, Deonarain MP (2010) Modulating the pharmacokinetics of therapeutic antibodies. Biotechnol Lett 32:609-622

Eriksen NT (2008) The technology of microalgal culturing. Biotechnol Lett 30:1525-1536

Fu YJ, Du J, Yang RJ, Yin LT, Liang AH (2010) Potential adenovirus-mediated gene therapy of glioma cancer. Biotechnol Lett 32:11-18

Haidar ZS, Hamdy RC, Tabrizian M (2009a) Delivery of recombinant bone morphogenetic proteins for bone regeneration and repair. Part A: current challenges in BMP delivery. Biotechnol Lett 31:1817-1824

Haidar ZS, Hamdy RC, Tabrizian M (2009b) Delivery of recombinant bone morphogenetic proteins for bone regeneration and repair. Part B: delivery systems for BMPs in orthopaedic and craniofacial tissue engineering. Biotechnol Lett 31:1825-1835

Hunt NC, Grover LM (2010) Cell encapsulation using biopolymer gels for regenerative medicine. Biotechnol Lett 32:733-742

Iwatani S, Yamada Y, Usuda Y (2008) Metabolic flux analysis in biotechnology processes. Biotechnol Lett 30:791-799

Kogan G, Soltes L, Stern R, Gemeiner P (2007) Hyaluronic acid: a natural biopolymer with a broad range of biomedical and industrial applications. Biotechnol Lett 29:17-25

Li J, Chase HA (2010) Applications of membrane techniques for purification of natural products. Biotechnol Lett 32: 601-608

Mansfeld J (2009) Plant phospholipases $\mathrm{A}_{2}$ : perspectives on biotechnological applications. Biotechnol Lett 31:1373-1380

Mashego MR, Rumbold K, De Mey M, Vandamme E, Soetaert W, Heijnen JJ (2007) Microbial metabolomics: past, present and future methodologies. Bioechnol Lett 29:1-16

Murphy CD (2010) Biodegradation and biotransformation of organofluorine compounds. Biotechnol Lett 32:351-359

Pandhal J, Wright PC (2010) N-Linked glycoengineering for human therapeutic proteins in bacteria. Biotechnol Lett 32:1189-1198

Proft T (2010) Sortase-mediated protein ligation: an emerging biotechnology tool for protein modification and immobilisation. Biotechnol Lett 32:1-10

Stolnik S, Shakesheff K (2009) Formulations for delivery of therapeutic proteins. Biotechnol Lett 31:1-11 